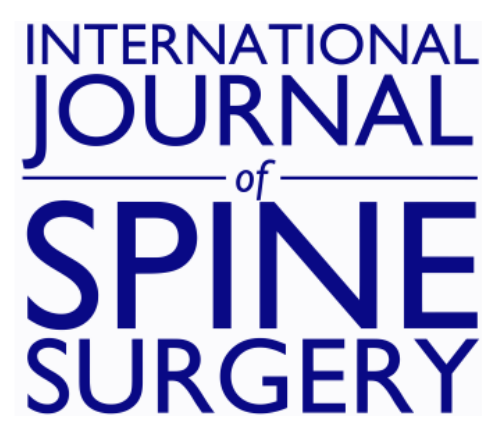

\title{
Editors' Commentary: The Effect of Vitamin D Deficiency on Outcomes of Patients Undergoing Elective Spinal Fusion Surgery: A Systematic Review and Meta-Analysis by Khalooeifard et al
}

Kai-Uwe Lewandrowski and Morgan P. Lorio

Int J Spine Surg published online 17 February 2022

http://ijssurgery.com/content/early/2022/02/17/8170

This information is current as of April 26, 2023.

Email Alerts Receive free email-alerts when new articles cite this article. Sign up at: http://ijssurgery.com/alerts 


\title{
Editors' Commentary: The Effect of Vitamin D Deficiency on Outcomes of Patients Undergoing Elective Spinal Fusion Surgery: A Systematic Review and Meta-Analysis by Khalooeifard et al
}

\author{
KAI-UWE LEWANDROWSKI, MD ${ }^{1}$ AND MORGAN P. LORIO, MD \\ ${ }^{1}$ Deputy Editor, International Journal of Spine Surgery, USA
}

The meta-analysis by Khalooeifard et al on the association of vitamin D deficiency and spinal fusion surgery functional outcomes assessed using the visual analog scale and Oswestry Disability Index was received with mixed evaluations by IJSS editors and reviewers. It prompted a thoughtful internal discussion regarding whether the article contained sufficient evidence to warrant publication. In the end, the editors decided to publish the authors' meta-analysis for the following reasons.

Vitamin D plays a critical role in calcium homeostasis and bone metabolism and aids in maintaining skeletal integrity and function. In addition, it has many other health benefits, including regulation of electrolyte reabsorption and the immune system. Unfortunately, its deficiency is widespread ${ }^{1-7}$ and has been implicated in many chronic diseases, such as Type I diabetes, ${ }^{8,9}$ rheumatoid arthritis,${ }^{10}$ hypertension, ${ }^{11}$ cardiovascular disease, ${ }^{10,12}$ and several common deadly cancers. ${ }^{13,14}$ Therefore, the IJSS editors believe that the authors' theory that vitamin D deficiency may impact clinical outcomes after spinal fusion was reasonable and worthy of investigation. The authors appropriately recognized the need for original clinical studies to investigate further the impact of vitamin D deficiency on spinal fusion and its correlation with pseudarthrosis. While the existing literature in this area is sparse, more concerning to the reviewers of this article was the sole use of functional visual analog scale and Oswestry Disability Index outcome measures without much regard to other confounding factors, including demographics, smoking, body mass index, diabetes, daily dairy consumption, vitamin D supplementation, patient education, and overall health status. Moreover, procedural aspects of the fusion procedure, including surgical approach and technique, graft type, and follow-up time, could not be adequately accounted for in the authors' meta-analysis. Yet, the authors did an excellent job of discussing these limitations of their meta-analysis. They provide a fresh look at an old subject that, until now, may not have been on the radar of many practicing spine surgeons who have to mitigate risks when stratifying patients for intervention.

The authors' meta-analysis implies that the many adverse effects of vitamin D deficiency may directly or indirectly affect spinal fusion outcomes. Due to the paucity of literature, the authors were unable to establish a clear, strong causal association between vitamin D levels and radiographic fusion outcomes, although they have demonstrated the validity of their findings by functional outcomes with their methodology. Fusion by definition is first and foremost evaluated radiographically for the presence of fusion (bridging bone) and the absence of motion at a motion segment. The inherent limitations of this meta-analysis would not, however, negate the encouragement of vitamin D supplementation in select spine patients as directed by concomitant endocrine consultation.

Ultimately, original research is required to more plausibly explain whether vitamin D levels should be routinely monitored and corrected preoperatively in high-risk patients, similar to hemoglobin A1C in patients with diabetes. ${ }^{15}$ The authors appropriately suggest higher-grade clinical studies with longer follow-up employing multivariate logistic regression analysis to substantiate further whether vitamin D deficiency can be validated as an independent predictor of pseudarthrosis. This team of editors hopes that the authors will follow through with that proposal to fill the knowledge gap in this underinvestigated area of spinal fusion surgery. 


\section{REFERENCES}

1. Ahmed AS, Ahmed T, Long KZ, et al. Prevalence and risk factors of vitamin D insufficiency and deficiency among 6-24-month-old underweight and normal-weight children living in an urban slum of Bangladesh. Public Health Nutr. 2017;20(10):1718-1728. doi:10.1017/S1368980015003353

2. Alipour S, Saberi A, Seifollahi A, Shirzad N, Hosseini L, et al. Risk factors and prevalence of vitamin D deficiency among Iranian women attending two university hospitals. Iran Red Crescent Med J. 2014;16(10):e15461. doi:10.5812/ircmj.15461

3. Alkerwi A, Sauvageot N, Gilson G, Stranges S, et al. Prevalence and correlates of Vitamin D deficiency and insufficiency in Luxembourg adults: evidence from the observation of cardiovascular risk factors (ORISCAV-LUX) study. Nutrients. 2015;7(8):6780-6796. doi:10.3390/nu7085308

4. Barney AM, Abraham VJ, Danda S, Cherian AG, Vanitha S, et al. Prevalence of Vitamin B12 deficiency and its associated risk factors among pregnant women of rural South India: a community-based cross-sectional study. Indian J Community Med. 2020;45(4):399-404. doi:10.4103/ijcm.IJCM_403_19

5. Bi X, Tey SL, Leong C, Quek R, Henry CJ, et al. Prevalence of Vitamin D deficiency in Singapore: its implications to cardiovascular risk factors. PLoS One. 2016;11(1):e0147616. doi:0.1371/ journal.pone.0147616

6. Choi R, Kim S, Yoo H, et al. High prevalence of vitamin D deficiency in pregnant Korean women: the first trimester and the winter season as risk factors for vitamin D deficiency. Nutrients. 2015;7(5):3427-3448. doi:10.3390/nu7053427

7. Deplanque $X$, Wullens A, Norberciak L. Prevalence and risk factors of vitamin D deficiency in healthy adults aged 18-65 years in northern France. Rev Med Interne. 2017;38(6):368-373. doi:10.1016/j.revmed.2016.12.013

8. Bener A, Alsaied A, Al-Ali M, et al. High prevalence of vitamin D deficiency in type 1 diabetes mellitus and healthy children. Acta Diabetol. 2009;46(3):183-189. doi:10.1007/s00592-008-0071-6

9. Raab J, Giannopoulou EZ, Schneider S, et al. Prevalence of vitamin D deficiency in pre-type 1 diabetes and its association with disease progression. Diabetologia. 2014;57(5):902-908. doi:10.1007/s00125-014-3181-4

10. Cecchetti S, Tatar Z, Galan P, et al. Prevalence of vitamin $\mathrm{D}$ deficiency in rheumatoid arthritis and association with disease activity and cardiovascular risk factors: data from the COMEDRA study. Clin Exp Rheumatol. 2016;34(6):984-990
11. Alkhatatbeh MJ, Smadi SA, Abdul-Razzak KK, Saadeh NA, et al. High prevalence of Vitamin D deficiency and correlation with Cystatin-C and other cardiovascular and renal risk biomarkers in patients with Type 2 diabetes mellitus complicated with hypertension. Curr Diabetes Rev. 2021;17(1):81-90. doi:10.2174/15733998 16666200516174352

12. Patel U, Yousuf S, Lakhani K, et al. Prevalence and outcomes associated with Vitamin D deficiency among indexed hospitalizations with cardiovascular disease and cerebrovascular disorder-A nationwide study. Medicines. 2020;7(11):E72. doi:10.3390/ medicines 7110072

13. Çidem M, Karacan I, Beytemur O, Kara S. Prevalence and risk factors for vitamin D deficiency in patients with widespread musculoskeletal pain. Turk J Med Sci. 2017;47(3):728-731. doi:10.3906/sag-1508-30

14. Parva NR, Tadepalli S, Singh P, et al. Prevalence of vitamin D deficiency and associated risk factors in the US population (20112012). Cureus. 2018;10(6):e2741. doi:10.7759/cureus.2741

15. Suresh KV, Wang K, Sethi I, et al. Spine surgery and preoperative hemoglobin, hematocrit, and hemoglobin A1c: a systematic review. Global Spine J. 2022;12(1):155-165. doi: $10.1177 / 2192568220979821$

Funding: The author(s) received no financial support for the research, authorship, and/or publication of this article.

Declaration of Conflicting Interests: The author(s) report no conflicts of interest or financial disclosures with respect to the research, authorship, and/or publication of this article.

Corresponding Author: Kai-Uwe Lewandrowski; business@tucsonspine.com

Published 15 February 2022

This manuscript is generously published free of charge by ISASS, the International Society for the Advancement of Spine Surgery. Copyright (C) 2022 ISASS. To see more or order reprints or permissions, see http:// ijssurgery.com. 